\title{
ПРАКТИКА САМОКОНТРОЛЯ ГЛИКЕМИИ И ЕГО ИНФОРМАТИВНОСТЬ У ПАЦИЕНТОВ С САХАРНЫМ ДИАБЕТОМ 2 ТИПА В РЕАЛЬНОЙ КЛИНИЧЕСКОЙ ПРАКТИКЕ
}

\author{
'Петров А.В., 'Стронгин Л.Г., ${ }^{2}$ Тарадайко Н.Ю.
}

'ФГБОУ ВО «Приволжский исследовательский медицинский университет» МЗ РФ, Нижний Новгород

2ГБУз НО «Нижегородская областная клиническая больница им.Н.А.Семашко», Нижний Новгород

ЦЕЛЬ: оценить применение самоконтроля гликемии пациентами с сахарным диабетом 2 типа, влияющие на него факторы и связь результатов с показателями гликированного гемоглобина $\left(\mathrm{HbA}_{1 \mathrm{c}}\right)$.

МАТЕРИАЛЫ И МЕТОДЫ: проанализированы данные 1196 пациентов, обследованных в 2010-2015 гг. в рамках клинических исследований кафедры, в том числе 939 - при работе мобильного диабетологического центра Нижегородской области. Пациенты были разделены на группы не проводящих регулярного измерения гликемии (СК0), измеряющих гликемию только натощак (CK1) и группу проводящих измерения натощак и в течение дня (CK2). Была собрана информация о минимальной и максимальной гликемии в течение последнего месяца, определены показатели средней гликемии, абсолютного (MAD) и относительного (MARD) размаха гликемии. Данные приведены в формате $\mathrm{M} \pm \mathrm{SD}$, для статистического анализа использовались оценка корреляции Спирмена, тесты Хи-квадрат Пирсона и Крускалла-Уоллеса.

РЕЗУЛЬТАТЫ: доля пациентов групп СК1 и СК2 составила 28\% и 24\% среди получавших таблетированные сахароснижающие препараты (ТСП); 38 и 36\% пациентов на инсулинотерапии; самоконтроль не проводили 47 и $26 \%$ пациентов в каждой подгруппе ( $<<0,0001)$. Самоконтроль был связан с достоверным улучшением гликемического контроля (HbA1c 7,5 \pm 1.8 vs.7.6 \pm 1.6 vs. $7.1 \pm 1.6 \%$ для групп СК0-1-2 пациентов на терапии ТСП, $p=0.04 ; 8.9 \pm 1,7$ vs. $8.5 \pm 1.5$ vs. $8.4 \pm 1.7$ на инсулинотерапии, $\mathrm{p}=0,01)$.

Результаты самоконтроля достоверно коррелировали с уровнем $\mathrm{HbA}_{1 c}(p<0.0001$ для всех показателей). Наибольшая сила корреляции отмечалась для среднего и максимального уровня гликемии ( $\mathrm{R}=0.63$ и 0,61 соответственно). Средней силы корреляция выявлена для минимального уровня гликемии $(\mathrm{R}=0.48)$ и слабая - для MAD и MARD ( $R=0.39$ и 0.24). У пациентов с гипогликемиями достоверно ниже были показатели минимальной гликемии (6.5 \pm 2.7 vs. $7.6 \pm 2.3$ ммоль/л, $\mathrm{p}=0,002)$ и $\mathrm{MARD}(38 \pm 42$ vs. $18 \pm 21 \%, \mathrm{p}=0,03)$.

Пациенты разных групп самоконтроля не имели значимых отличий по возрасту, длительности диабета, распространенности гипертонической болезни, ИБС и ОНМК, уровню альбуминурии. Более интенсивный самоконтроль был связан с несколько большим уровнем креатинина (72 22 vs. $68 \pm 20$ vs. $66 \pm 23$ в группах CK2, CK1 и СК0 соответственно, $p=0,003)$, но меньшей распространенностью ретинопатии ( $56 \%$ vs. $51 \%$ vs. $71 \%, \mathrm{p}=0,003)$.

Выводы: значительное количество пациентов с сахарным диабетом 2 типа не проводит самоконтроль гликемии или же ограничивается измерением гликемии натощак, у этих пациентов отмечается худший гликемический контроль. Убедительных различий по распространенности микрососудистых осложнений не получено, что может быть обусловлено отличиями течения заболевания.

Оценка минимального и максимального уровня гликемии при минимальной затрате времени позволяет получить информацию, характеризующую качество управления сахарным диабетом. Хроническую гипергликемию лучше отражают показатели средней и максимальной гликемии, а риск гипогликемий - минимальная гликемия и MARD.

Показатели минимального и максимального уровня гликемии могут рассматриваться как наиболее простой вариант оценки углеводного обмена при невозможности детального анализа дневников самоконтроля, памяти глюкометра и обсуждения результатов самоконтроля с пациентами. 